California GAMA Special Study: Stable isotopic composition of boron in groundwater - analytical method development

Gary R. Eppich, Josh B. Wimpenny*, Qing-zhu Yin*, and Bradley K. Esser

Lawrence Livermore National Laboratory

*University of California, Davis

October, 2011

Final report for the California State Water Resources Control Board GAMA Special Studies Task 10.4 : Development of New Wastewater Indicator Methods 


\section{Disclaimer}

This document was prepared as an account of work sponsored by an agency of the United States government. Neither the United States government nor Lawrence Livermore National Security, LLC, nor any of their employees makes any warranty, expressed or implied, or assumes any legal liability or responsibility for the accuracy, completeness, or usefulness of any information, apparatus, product, or process disclosed, or represents that its use would not infringe privately owned rights. Reference herein to any specific commercial product, process, or service by trade name, trademark, manufacturer, or otherwise does not necessarily constitute or imply its endorsement, recommendation, or favoring by the United States government or Lawrence Livermore National Security, LLC. The views and opinions of authors expressed herein do not necessarily state or reflect those of the United States government or Lawrence Livermore National Security, LLC, and shall not be used for advertising or product endorsement purposes.

\section{Auspices Statement}

This work performed under the auspices of the U.S. Department of Energy by Lawrence Livermore National Laboratory under Contract DE-AC52-07NA27344. 


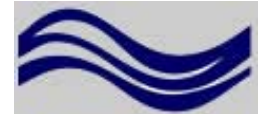

Water Boards

\section{GAMA: GROUNDWATER AMBIENT \\ Monitoring \& ASSESSMENT PRogram \\ SPECIAL STUDY}

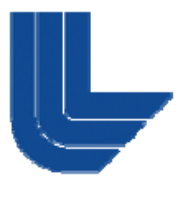

\section{California GAMA Special Study: Stable isotopic composition of boron in groundwater - analytical method development}

By Gary R. Eppich, Josh B. Wimpenny*, Qing-zhu Yin*, and Bradley K. Esser Lawrence Livermore National Laboratory

*University of California, Davis
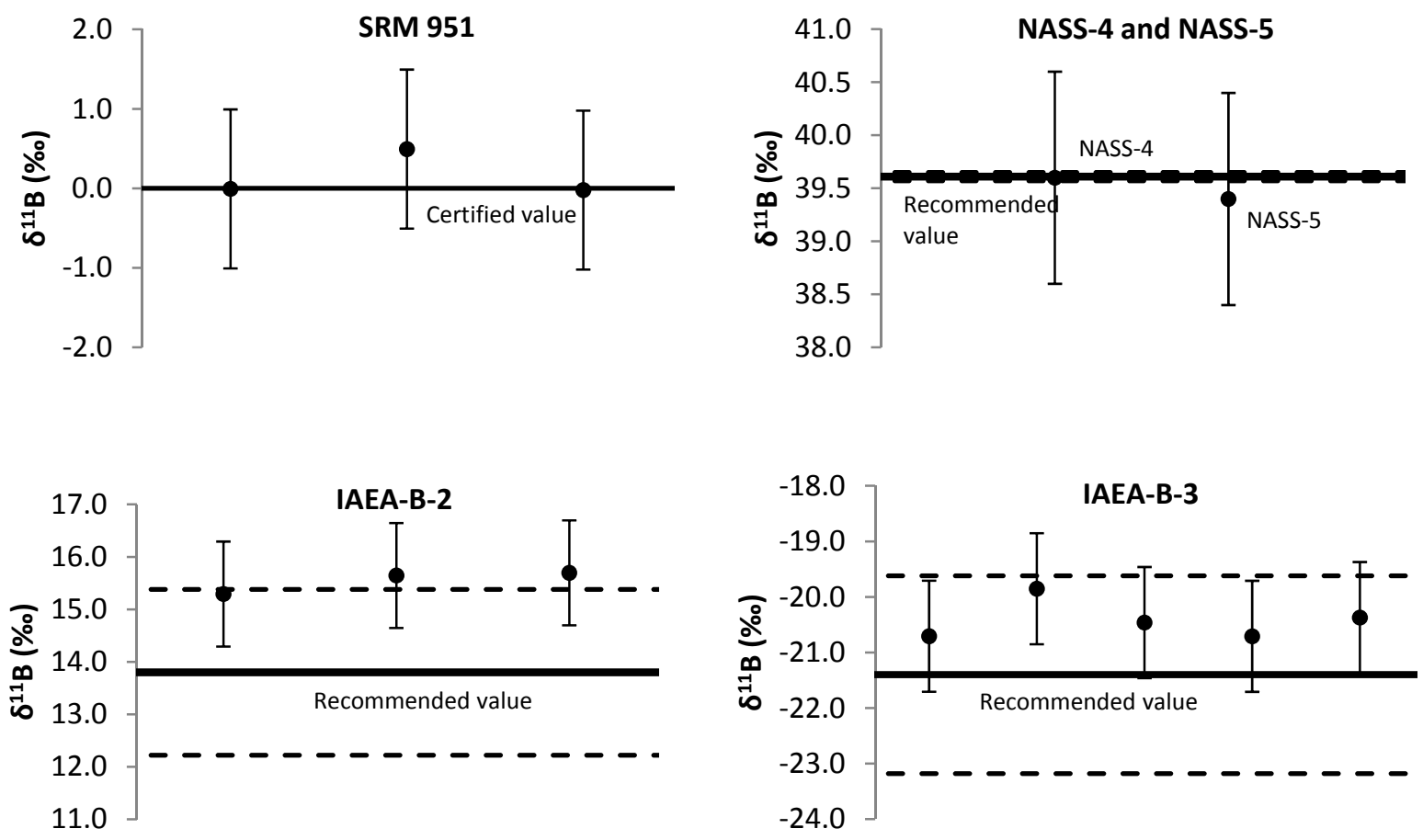

Final Report for GAMA Special Studies Task 10.4

Development of New Wastewater Indicator Methods LLNL-TR-498360

Prepared in cooperation with the California State Water Resource Control Board October 2011 


\section{Suggested citation:}

Eppich, G.R., Wimpenny, J.B., Yin, Q.-Y., and Esser, B.K. California GAMA Special Study: Stable isotopic composition of boron in groundwater - analytical method development, LLNL-TR498360, 29 pages. 


\title{
California GAMA Special Study: Stable isotopic composition of boron in groundwater - Analytical method development
}

\author{
Gary R. Eppich ${ }^{a}$, , Josh B. Wimpenny ${ }^{b}$, Qing-zhu Yin ${ }^{b}$, and Bradley K. Esser ${ }^{a}$ \\ a Lawrence Livermore National Laboratory \\ ${ }^{b}$ University of California - Davis
}

\section{INTRODUCTION}

Boron is a ubiquitous dissolved constituent in natural waters due to its high solubility, natural occurrence in continental crust, and anthropogenic use in fertilizers, consumer products, and other non-natural sources. The two stable isotopes of boron, ${ }^{10} \mathrm{~B}$ and ${ }^{11} \mathrm{~B}$ (natural abundances $\approx$ 19.9 and $\approx 80.1$ atom percent, respectively), undergo isotopic fractionation due to a variety of chemical processes related to boron speciation $\left({ }^{10} \mathrm{~B}\right.$ is preferentially incorporated into $\mathrm{B}(\mathrm{OH})_{4}$ versus $\mathrm{B}(\mathrm{OH})_{3}$, e.g. Byrne et al., 2006). The isotopic composition of dissolved boron in groundwater can be used to determine the source(s) of boron; this information can be used to infer the source(s) of other co-migrating contaminants (e.g. nitrate, pharmaceuticals, etc.). Boron behaves as a conservative element in groundwater and surface water systems (Barth, 2000), and the isotopic signature of boron is most useful in conjunction with other stable and radiogenic isotope systems (e.g. $\delta^{18} \mathrm{O}, \delta^{15} \mathrm{~N}, \delta^{13} \mathrm{C},{ }^{87} \mathrm{Sr} /{ }^{86} \mathrm{Sr}$; Tirez et al., 2010; Widory et al., 2004; Widory et al., 2005) to determine the source(s) of contaminants of interest.

We present here a method for boron purification in natural water samples (groundwater, surface water, and seawater) by ion exchange chemistry and measurement of boron isotopic composition by MC-ICP-MS. These methods can be applied to samples with boron concentrations as low as $10 \mathrm{ppb}$ with precision on $\delta^{11} \mathrm{~B}$ measurements better than $\pm 1 \%$. We utilize boron isotopic measurements of boric acid, groundwater, and seawater standards to validate the methods. We also present boron isotopic measurements of San Diego County domestic well samples to demonstrate how these methods can be applied to any study of natural water samples.

\section{SAMPLE COLLECTION}

Groundwater samples were collected by the California State Water Resources Control Board (SWRCB) using sample collection techniques described in Singleton et al. (2011). In short, samples were collected unfiltered from wells and surface waters using standard water collection methods in clean $50 \mathrm{~mL}$ polyethylene centrifuge tubes and stored refrigerated or frozen at Lawrence Livermore National Laboratory. Boron concentration was measured by ion chromatography in separate splits of each sample by laboratories subcontracted by the SWRCB. Recommendations for sampling and handling groundwater for determination of boron isotopic composition are summarized in Table 1. 


\section{CHEMICAL PURIFICATION METHODS}

In order to measure boron isotopic composition precisely and accurately, the dissolved boron must be chemically separated from other elements (e.g. $\mathrm{Na}^{+}, \mathrm{Mg}^{2+}, \mathrm{Cl}^{-}, \mathrm{SO}_{4}{ }^{2-}$ ) present in natural waters (Appendix A "Chemical Purification of Boron in Groundwater Samples for Isotopic Analysis" for further information). We used an ion-exchange technique adapted from methods described by Lemarchand et al. (2002a) and Guerrot et al. (2011). This technique utilizes a boron-specific ion exchange resin (Amberlite IRA 743, mfg. Rohm and Haas) which is highly compatible with boron in neutral to basic solution and highly incompatible with boron in acidic solution (Lemarchand et al., 2002a). To prepare the resin for use in this technique, the resin was crushed and sieved to 100-200 mesh size, then washed them least three times each with 18.2 $\mathrm{M} \Omega-\mathrm{cm} \mathrm{H}_{2} \mathrm{O}$ (hereafter, $\mathrm{MQ} \mathrm{H}_{2} \mathrm{O}$ ), $2 \% \mathrm{HNO}_{3}, \mathrm{MQ} \mathrm{H}_{2} \mathrm{O}, 2 \% \mathrm{NH}_{4} \mathrm{OH}$, and $\mathrm{MQ} \mathrm{H}_{2} \mathrm{O}$. All acids and bases used in this study were ultrapure grade and obtained from SeaStar Chemicals.

Whenever possible, enough water was used to purify approximately $500 \mathrm{ng}$ of dissolved boron. Prior to ion-exchange chemistry, samples were dried down on a hot plate, then dissolved in 1 $\mathrm{mL} \mathrm{MQ} \mathrm{H}_{2} \mathrm{O}$. Care was taken to remove samples from heat immediately prior to achieving dryness to prevent boron loss and potential isotopic fractionation due to volatilization and sublimation (e.g., Gaillardet et al., 2001). To ensure samples were $\mathrm{pH} \geq 7,25 \mu \mathrm{L}$ of $2 \% \mathrm{NH}_{4} \mathrm{OH}$ was added to each sample prior to loading on the resin bed. Each sample was loaded onto a $500 \mu \mathrm{L}$ resin bed. Boron separation was performed following the procedure listed in Table 2. The fraction of eluate containing boron was collected, dried down, dissolved in $1 \mathrm{~mL} 2 \% \mathrm{HNO}_{3}$, and transferred to clean $2 \mathrm{~mL}$ polyethylene centrifuge tubes for storage prior to analysis by MCICP-MS.

\section{MASS SPECTROMETRY}

Boron isotope composition measurements were performed using a Thermo Neptune MC-ICPMS at University of California - Davis (see Appendix B “Measurement of $\delta^{\mathbf{1 1}} \mathbf{B}$ in Groundwater Samples" for further information). Faraday cups were configured so that ${ }^{11} B$ was collected in $\mathrm{H} 3$ and ${ }^{10} \mathrm{~B}$ was collected in L3. Samples were screened for strength of B signal prior to analysis. Dilutions were prepared for each sample to match within $25 \%$ of the voltage of a ${ }^{11} \mathrm{~B}$ signal of an SRM 951 solution (typically 50 to 100 ppb). Samples were introduced to the plasma in $2 \%$ $\mathrm{HNO}_{3}$ using a sample introduction system consisting of a PFA nebulizer ported into a glass spray chamber at a flow rate of $\sim 50 \mu \mathrm{L} / \mathrm{min}$. A standard nickel sampling cone and a high-sensitivity nickel X-skimmer cone were used. Analyses were performed in low-resolution mode. Sample gas flow rate was tuned to 1.2 to $1.3 \mathrm{~L} / \mathrm{min}$, which provided maximum stability and sensitivity. Each analysis involved $208 \mathrm{~s}$ integrations.

Total procedural blanks were typically negligible. The primary source of error in the measurement was caused by the boron memory effect (e.g., Al-Ammar et al., 2000; Foster, 2008). Boron tended to sorb to components of the MC-ICP-MS sample introduction system, resulting in elevated backgrounds that are difficult to remove with $2 \% \mathrm{HNO}_{3}$ during wash-out steps. To reduce elevated blank measurements associated with the memory effect, a wash step 
using $2 \% \mathrm{HNO}_{3}+0.05 \mathrm{M} \mathrm{HF}$ was used to remove boron contamination within the spray chamber. This wash step was run for 2-3 minutes prior to a wash step of $2 \% \mathrm{HNO}_{3}$, which was run for 10 minutes. Blank measurements were taken after these wash steps in the $2 \% \mathrm{HNO}_{3}$ wash. This wash-out routine was typically successful in removing the background ${ }^{11} \mathrm{~B}$ signal to $<5 \%$ of the ${ }^{11} \mathrm{~B}$ signal on the standard 100 ppb SRM 951, although in a few cases, blank measurements were as high as $10 \%$. Blank measurements were typically $20-30 \mathrm{mV}$ on ${ }^{11} \mathrm{~B}$. Blank measurements were performed before and after each sample and standard measurement. All measurements of samples and standards were corrected for error introduced by the memory effect by subtracting blank measurements of ${ }^{11} \mathrm{~B}$ and ${ }^{10} \mathrm{~B}$ from the measured signal in samples and standards.

The isotopic composition of boron is expressed as a ratio of the two naturally-occurring stable isotopes ${ }^{11} \mathrm{~B}$ and ${ }^{10} \mathrm{~B}$ (natural ${ }^{11} \mathrm{~B} /{ }^{10} \mathrm{~B}=4.025$ ) relative to the isotopic composition of boric acid standard SRM 951 (certified ${ }^{11} \mathrm{~B} /{ }^{10} \mathrm{~B}=4.044$ ). These ratios are expressed using delta notation $\left(\delta^{11} \mathrm{~B}\right)$ as parts per thousand $(\%)$, calculated using Equation 1 , where $R_{\text {sample }}={ }^{11} \mathrm{~B} /{ }^{10} \mathrm{~B}$ of sample, and $R_{S R M} 951$ (1) and $R_{S R M} 951(2)={ }^{11} B /{ }^{10} B$ of SRM 951 measured before and after each sample measurement.

Equation 1:

$$
\delta^{11} B_{\text {sample }}(\%)=\left[\frac{R_{\text {sample }}}{\left(R_{\text {SRM } 951(1)}+R_{\text {SRM } 951(2)}\right) \div 2}-1\right] \times 1000
$$

Samples were analyzed using a standard-sample-standard bracketing routine to correct for instrumental mass bias shift over time, following the procedures outlined in Lemarchand et al. (2002a), Foster (2008), and Guerrot et al. (2011). The mean $\delta^{11} B$ value of SRM 951 measurements used for bracketing each analysis, bracketed to SRM 951 analyses before and after, was $0.00 \pm 0.64 \%$ (all uncertainties are reported as $2 \sigma$ ).

\section{MEASUREMENT ACCURACY AND PRECISION}

To assess the accuracy and precision of the purification method and analytical routine we employed in this study, we performed total procedural replicates of five reference materials:

- Boric acid standard SRM 951, which is $0 \%$ by definition;

- IAEA-B-2, a groundwater standard from the lower basin of the Cecina River, Italy, with a recommended $\delta^{11} \mathrm{~B}$ value of $+13.80 \pm 0.79 \%$ (Gonfiantini et al., 2003);

- IAEA-B-3, a groundwater standard from the upper basin of the Cecina River, Italy, with a recommended $\delta^{11} \mathrm{~B}$ value of $-21.40 \pm 0.89 \%$ (Gonfiantini et al., 2003); 
- NASS-4 and NASS-5, seawater standards, with $\delta^{11} \mathrm{~B}=+39.61 \pm 0.04 \%$ o (Foster et al., 2010).

We performed three total procedural replicates of SRM 951 (Table 3); the mean $\delta^{11} \mathrm{~B}$ value of the three measurements was $+0.2 \pm 0.6 \%$. There results were within $2 \sigma$ uncertainty to the certified SRM 951 value of $0 \%$, demonstrating that the chemical purification technique did not induce isotopic fractionation due to incomplete recovery of boron from the resin bed (Lemarchand et al., 2002b), and/or that sample dry-down steps did not induce boron isotopic fractionation (Gaillardet et al., 2001).

We also performed total procedural replicates for IAEA-B-2 $(n=3)$ and IAEA-B-3 $(n=5)$. Our mean $\delta^{11} B$ results for IAEA-B-2 and IAEA-B-3 were $+15.5 \pm 0.4 \%$ and $-20.4 \pm 0.7 \%$, respectively (Table 3 ). These results are outside of the $1 \sigma$ uncertainty of the recommended PTIMS $\delta^{11} \mathrm{~B}$ values reported by Gonfiantini et al. (2003); our results are higher by $1.7 \%$ o for IAEAB-2 and $1.0 \%$ for IAEA-B-3. However, our measurements do typically within $2 \sigma$ uncertainty of the recommended values. One possible explanation for these data is the confounding factor of space-charge effects in the plasma, caused by the interference of contaminating elements other than boron in the analyte solution due to incomplete boron purification. This is unlikely, as Guerrot et al. (2011) demonstrated that the presence of $\mathrm{Na}^{+}, \mathrm{Ca}^{2+}, \mathrm{K}^{+}$, and $\mathrm{Mg}^{2+}$ cause large negative deviations in $\delta^{11} \mathrm{~B}$, not the small positive deviations we observe. Gonfiantini et al. (2003) acknowledge shortcomings in their interlaboratory comparison, including inconsistencies in chemical purification and data calculation methods used among the participating laboratories, and a limited number of laboratories submitting results in time for publication (only four laboratories submitted P-TIMS results for IAEA-B-2, and only five for IAEA-B-3). Therefore, we suggest that the recommended P-TIMS $\delta^{11} B$ values for IAEA-B-2 and IAEA-B-3 are only known to $2 \sigma$ at best, and we do not interpret the small positive deviations from the recommended values as evidence of systematic offset. Rather, our $\delta^{11} B$ results for IAEA-B-2 and IAEA-B-3 are consistent with seven total procedural Neptune MC-ICP-MS analyses performed by Guerrot et al. (2011) on these standards (+14.65 $\pm 0.44 \%$ ond $-21.37 \pm 0.42 \%$ o for IAEA-B-2 and IAEA-B-3, respectively).

We also performed chemical separations and isotopic measurement for NASS-4 $(n=1)$ and NASS-5 $(n=1)$ seawater standards. Although these standards do not have a characterized boron isotopic composition, Foster et al. (2010) have shown that the $\delta^{11} \mathrm{~B}$ of seawater is homogeneous worldwide. We measured NASS- $4=+39.6 \pm 1.0 \%$ and NASS-5 $\delta^{11} \mathrm{~B}=+39.4 \pm 0.9$ $\%$, within error of the $\delta^{11} \mathrm{~B}$ value proposed by Foster et al. (2010). This result gives us further confidence that our chemical separations and isotopic measurements of IAEA-B-2 and IAEA-B-3 are not causing systematic offset from their true values.

We performed total procedural duplicates for three groundwater samples from San Diego County domestic wells (Table 4). Our results for these three samples showed that deviations in $\delta^{11} \mathrm{~B}$ between separate chemical purifications for the same samples were less than $0.7 \%$. These results are consistent with our results for total procedural duplicates for the standards, 
and strongly suggests that the methods described in this study are reproducible for a given sample by better than $1 \%$.

In addition to chemistry duplicates, we assessed measurement precision using replicate measurements of samples performed throughout the course of a particular analytical session (Table 3). Each sample analysis was normalized to bracketing SRM 951 standard analyses measured before and after. Our results showed that these analyses are reproducible to better than $1 \%$, and in most cases, are reproducible to better than $0.5 \%$. These findings demonstrate that the standard-sample-standard bracketing routine is highly reproducible, and the results are not significantly affected by changes in mass bias over time throughout the course of a given run.

\section{DATA QUALITY OBJECTIVES and DATA REPORTING}

Based on data from certified reference standards and duplicate analyses of groundwater samples reported in this study, we have developed figures of merit and data quality objectives for the determination of groundwater boron isotopic composition by multi-collector ICPMS as performed by LLNL staff (see Table 5). The DQOs were selected to be routinely achievable and to be sufficiently stringent to allow using boron isotopic signature as a wastewater indicator

Groundwater boron isotopic data generated for the State of California GAMA program will be reported in a format compatible with Geotracker GAMA. LLNL has requested a valid value parameter for boron isotopic composition, and has developed an Electronic Data File Control Limit (EDFCL) file for this process. More information can be found in Appendix C ("Submission of Groundwater Boron Isotopic Data to Geotracker GAMA in EDF Format").

\section{CONCLUSIONS}

We successfully demonstrated the accuracy and reproducibility of boron isotopic MC-ICP-MS measurements of purified natural water samples (groundwater, surface water, seawater) using a modified ion-exchange purification technique. The methods described in this study can be applied to future studies of natural waters.

\section{ACKNOWLEDGEMENTS}

Dr. Ross Williams (LLNL) provided invaluable guidance and advice in the early development of the chemistry and mass spectrometry. Richard Bibby provided assisted in the development of an electronic data deliverable for boron isotopic composition in groundwater. 

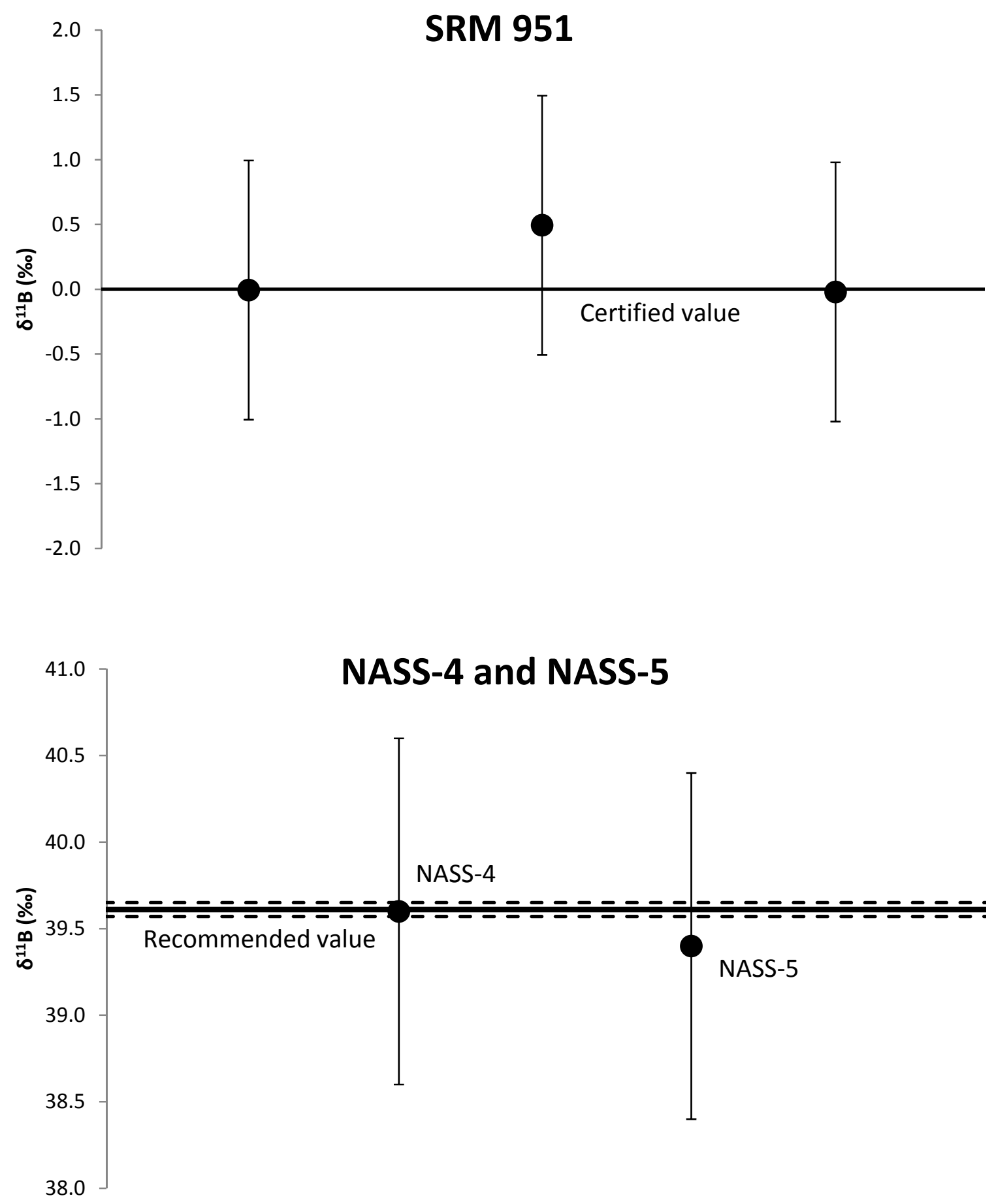

Figure 1. Results of $\delta^{11} \mathrm{~B}$ measurements of boric acid and seawater standards. Certified value for SRM 951 is $0 \%$ by definition; recommended values for NASS-4 and NASS-5 are from Foster et al. (2010). Dashed lines represent $2 \sigma$ uncertainty of recommended values. Error bars are \pm 1 $\%$, based on a conservative estimate extrapolated from total procedural replicates of standards and samples (see Table 2 ), which are $< \pm 1 \%$. 


\section{IAEA-B-2}

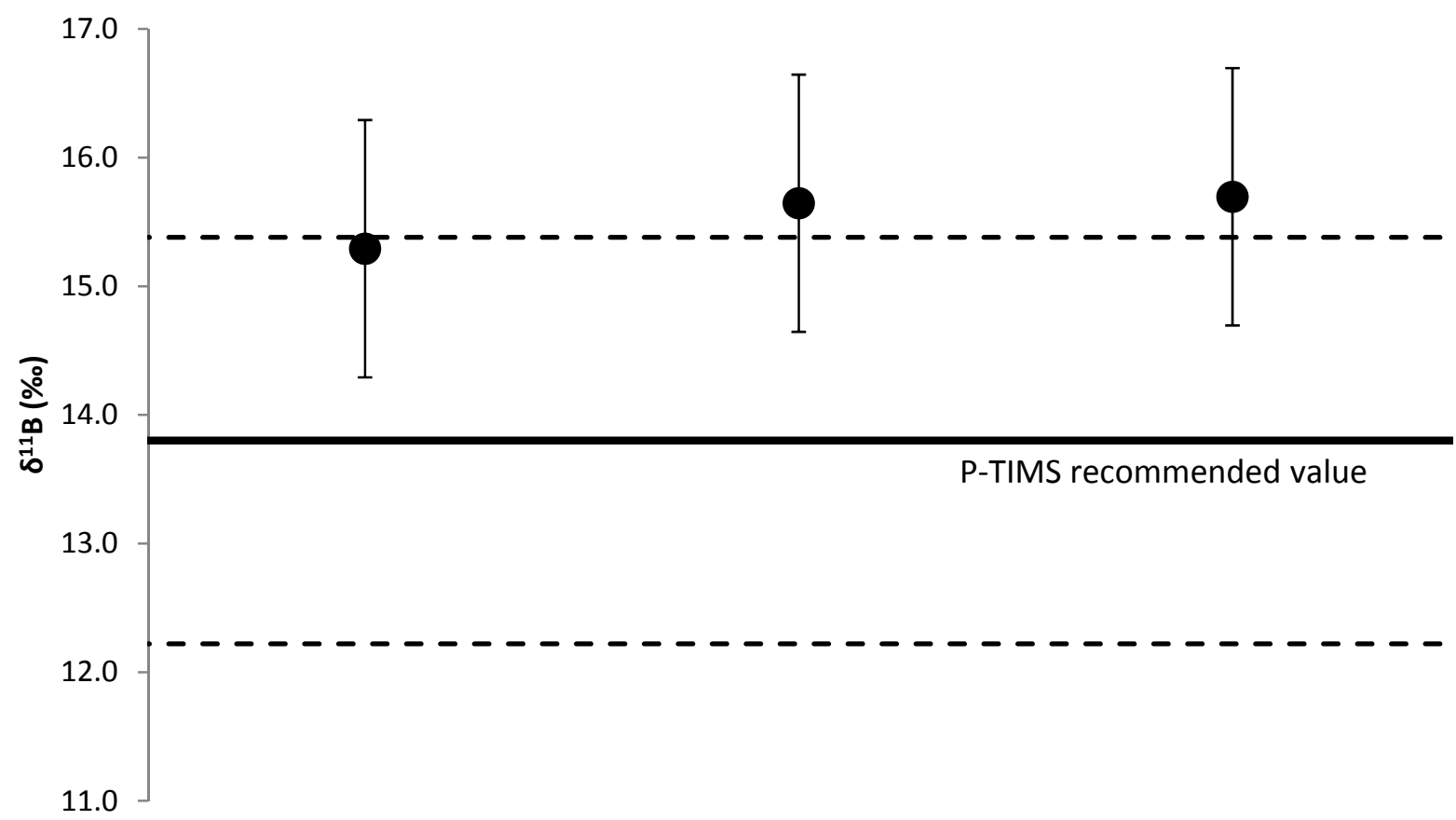

IAEA-B-3

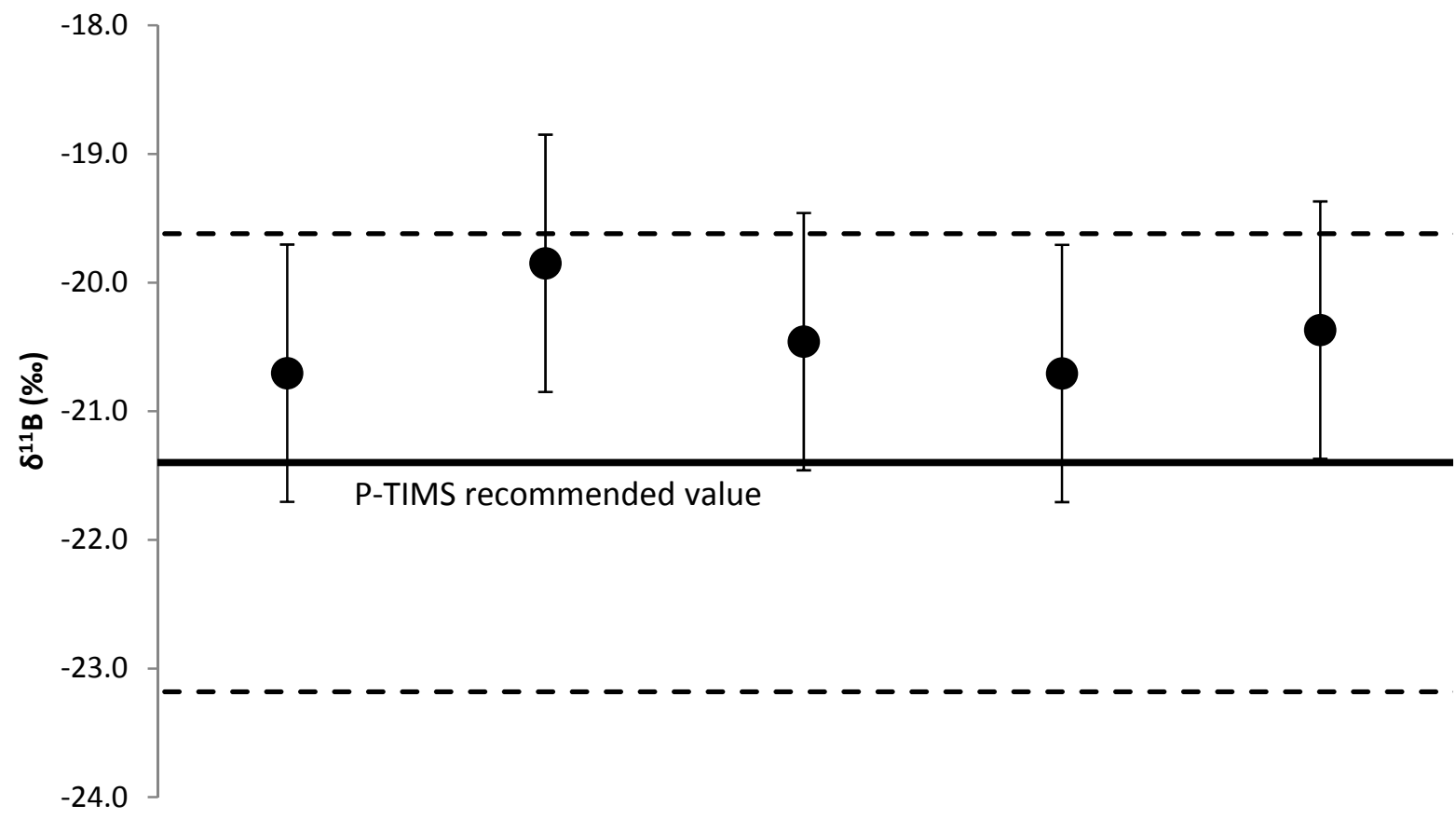

Figure 2. Results of $\delta^{11} \mathrm{~B}$ measurements of groundwater standards. Recommended values are from Gonfiantini et al. (2003). Dashed lines represent $2 \sigma$ uncertainty of recommended values. Error bars are $\pm 1 \%$, based on a conservative estimate extrapolated from total procedural replicates of standards and samples (see Table 2 ), which are $< \pm 1 \%$. 
Table 1:

Sampling and Handling Requirements for Groundwater Boron Isotopic Composition

\begin{tabular}{|l|l|}
\hline Analyte & Groundwater boron isotopic composition $\left(\delta^{11} \mathrm{~B}\right)$ \\
\hline Container & Plastic (Do not use borosilicate glass containers) \\
\hline Minimum sample size & $\begin{array}{l}\text { A minimum of } 500 \mathrm{ng} \text { boron is required for analysis. } \\
\text { Collect } 10 \mathrm{~mL} \text { for samples containing }>50 \mu \mathrm{B} / \mathrm{L} . \\
\text { Collect } 50 \mathrm{~mL} \text { for samples containing }<50 \mu \mathrm{g} / \mathrm{L} .\end{array}$ \\
\hline Recommended Preservation & $\begin{array}{l}\text { We recommend field filtration to less than } 0.45 \mu \mathrm{m}, \text { followed by } \\
\text { field acidification with ultrapure } \mathrm{HNO}_{3} \text { to less than pH } 2 . \\
\text { Preservation in field, however, is not strictly necessary. Unfiltered, } \\
\text { unacidified samples and filtered, unacidified samples are both } \\
\text { acceptable. Unpreserved samples should be shipped overnight } \\
\text { within } 48 \text { hours of collection, and will be filtered and acidified upon } \\
\text { receipt in the laboratory. Unfiltered, acidified samples are not } \\
\text { acceptable. }\end{array}$ \\
\hline Recommended hold & One year. \\
\hline Regulatory hold & Not applicable. \\
\hline
\end{tabular}

Table 2.

Chemical separation techniques for boron purification

A protocol for liquid samples using Amberlite IRA 743 ion-exchange resin, adapted from Lemarchand et al. (2002a)and Guerrot et al. (2011).

\begin{tabular}{l|l|l}
\hline Procedure & Reagent & Volume \\
\hline Condition resin & $2 \% \mathrm{HNO}_{3}$ & $4 \mathrm{~mL}$ \\
& $\mathrm{MQ} \mathrm{H}_{2} \mathrm{O}$ & $2 \mathrm{~mL}$ \\
& $2 \% \mathrm{NH}_{4} \mathrm{OH}$ & $4 \mathrm{~mL}$ \\
& $\mathrm{MQ} \mathrm{H}_{2} \mathrm{O}$ & $2 \mathrm{~mL}$ \\
Load sample & $\mathrm{Sample}^{2}$ & $1 \mathrm{~mL}$ \\
$\begin{array}{l}\text { Rinse beaker } \\
\text { Add reagent to sample beaker, } \\
\text { mix, add to column }\end{array}$ & $\mathrm{MQ} \mathrm{H}_{2} \mathrm{O}$ & $0.5 \mathrm{~mL}$ \\
$\begin{array}{l}\text { Rinse beaker } \\
\text { Add reagent to sample beaker, } \\
\text { mix, add to column }\end{array}$ & $\mathrm{MQ} \mathrm{H}_{2} \mathrm{O}$ & $0.5 \mathrm{~mL}$ \\
Rinse column & & \\
Collect boron & $2 \% \mathrm{NH}_{4} \mathrm{OH}$ & $2 \mathrm{~mL}$ \\
\hline
\end{tabular}


Table 3.

Measured boron isotopic composition of processed reference standards.

$\delta^{11} \mathrm{~B}$ measurements of chemistry duplicates of standards described in this study. The certified value of SRM 951 is $0 \%$ by definition. Recommended $\delta^{11} B$ values for IAEA-B- 2 and IAEA-B-3 are from Gonfiantini et al. (2003), and recommended $\delta^{11} B$ values for NASS-4 and NASS-5 are from Foster et al. (2010).

\begin{tabular}{lll}
\hline Standard & Certified Value (\%) & Measured Value (\%o) \\
\hline SRM 951 (1) & 0 & 0.0 \\
SRM 951 (2) & & 0.5 \\
SRM 951 (3) & & 0.0 \\
mean $\pm 2 \sigma$ & & $0.2 \pm 0.6$ \\
\hline \hline Standard & Recommended & Measured Value (\%o) \\
& Value (\%o $\pm 2 \sigma)$ & \\
\hline IAEA-B-2 (1) & $13.80 \pm 1.58$ & 15.3 \\
IAEA-B-2 (2) & & 15.6 \\
IAEA-B-2 (3) & & 15.7 \\
mean $\pm 2 \sigma$ & & $15.5 \pm 0.4$ \\
\hline IAEA-B-3 (1) & $-21.40 \pm 1.78$ & -20.7 \\
IAEA-B-3 (2) & & -19.9 \\
IAEA-B-3 (3) & & -20.5 \\
IAEA-B-3 (4) & & -20.7 \\
IAEA-B-3 (5) & & -20.4 \\
mean $\pm 2 \sigma$ & & $-20.4 \pm 0.7$ \\
\hline NASS-4 & $39.61 \pm 0.04$ & 39.6 \\
\hline NASS-5 & $39.61 \pm 0.04$ & 39.4 \\
\hline
\end{tabular}


Table 4.

Reproducibility of blank-corrected $\delta^{11 B}$ measurements of San Diego County domestic well samples.

Calculation of $\delta^{11} \mathrm{~B}$ is relative to blank-corrected bracketing SRM 951 isotopic standards. Chemistry duplicates are separate aliquots of the same sample, Measurement duplicates are individual measurements of the same sample using different bracketing SRM 951 isotopic standards.

\begin{tabular}{|c|c|c|c|c|c|c|}
\hline Sample & Run \# & ${ }^{10} \mathrm{~B}(\mathrm{~V})$ & ${ }^{11} \mathrm{~B}(\mathrm{~V})$ & ${ }^{11} \mathrm{~B} /{ }^{10} \mathrm{~B}$ & $\delta^{11} \mathrm{~B}(\% \circ)$ & $2 \sigma$ \\
\hline SD 920 & 1 & 2.44E-01 & $1.16 \mathrm{E}+00$ & 4.7520 & 36.93 & \\
\hline SD 920 DUP & 1 & $2.52 \mathrm{E}-01$ & $1.20 \mathrm{E}+00$ & 4.7523 & 37.05 & \\
\hline Mean & & & & & 36.99 & 0.09 \\
\hline SD 816 & 1 & $1.38 \mathrm{E}-01$ & $6.50 \mathrm{E}-01$ & 4.7046 & 24.66 & \\
\hline SD 816 DUP & 1 & $1.50 \mathrm{E}-01$ & 7.06E-01 & 4.7038 & 24.63 & \\
\hline Mean & & & & & 24.64 & 0.02 \\
\hline SD 923 & 1 & $2.30 \mathrm{E}-01$ & $1.08 \mathrm{E}+00$ & 4.6907 & 24.31 & \\
\hline SD 923 DUP & 1 & $2.09 \mathrm{E}-01$ & $9.85 \mathrm{E}-01$ & 4.7012 & 24.99 & \\
\hline Mean & & & & & 24.65 & 0.48 \\
\hline \multirow[t]{3}{*}{ SD 838} & 1 & $2.94 \mathrm{E}-01$ & $1.39 \mathrm{E}+00$ & 4.7253 & 34.12 & \\
\hline & 2 & 2.67E-01 & $1.26 \mathrm{E}+00$ & 4.7234 & 33.61 & \\
\hline & 3 & $2.69 \mathrm{E}-01$ & $1.27 \mathrm{E}+00$ & 4.7231 & 33.56 & \\
\hline Mean & & & & & 33.77 & 0.61 \\
\hline \multirow[t]{3}{*}{ SD 845} & 1 & $2.21 \mathrm{E}-01$ & $1.05 E+00$ & 4.7424 & 37.77 & \\
\hline & 2 & $2.22 \mathrm{E}-01$ & $1.05 E+00$ & 4.7435 & 37.95 & \\
\hline & 3 & $2.25 \mathrm{E}-01$ & $1.07 \mathrm{E}+00$ & 4.7428 & 37.80 & \\
\hline Mean & & & & & 37.84 & 0.19 \\
\hline \multirow[t]{3}{*}{ SD 801} & 1 & $1.56 \mathrm{E}-01$ & 7.48E-01 & 4.7837 & 46.48 & \\
\hline & 2 & $1.66 \mathrm{E}-01$ & 7.96E-01 & 4.7861 & 46.30 & \\
\hline & 3 & $1.66 \mathrm{E}-01$ & 7.97E-01 & 4.7886 & 46.94 & \\
\hline Mean & & & & & 46.57 & 0.66 \\
\hline \multirow[t]{3}{*}{ SD 848} & 1 & $2.36 \mathrm{E}-01$ & $1.12 \mathrm{E}+00$ & 4.7437 & 37.19 & \\
\hline & 2 & $2.34 \mathrm{E}-01$ & $1.11 \mathrm{E}+00$ & 4.7432 & 37.02 & \\
\hline & 3 & $2.31 \mathrm{E}-01$ & $1.09 \mathrm{E}+00$ & 4.7446 & 37.28 & \\
\hline Mean & & & & & 37.16 & 0.26 \\
\hline \multirow[t]{3}{*}{ SD 919} & 1 & $2.18 \mathrm{E}-01$ & $1.06 \mathrm{E}+00$ & 4.8495 & 60.20 & \\
\hline & 2 & $2.22 \mathrm{E}-01$ & $1.08 \mathrm{E}+00$ & 4.8509 & 60.59 & \\
\hline & 3 & $2.21 \mathrm{E}-01$ & $1.07 \mathrm{E}+00$ & 4.8522 & 60.73 & \\
\hline Mean & & & & & 60.50 & 0.55 \\
\hline \multirow[t]{3}{*}{ SD 877} & 1 & $2.04 \mathrm{E}-01$ & $9.55 \mathrm{E}-01$ & 4.6877 & 24.87 & \\
\hline & 2 & $2.04 \mathrm{E}-01$ & $9.55 \mathrm{E}-01$ & 4.6883 & 24.88 & \\
\hline & 3 & $1.96 \mathrm{E}-01$ & $9.18 \mathrm{E}-01$ & 4.6870 & 24.62 & \\
\hline Mean & & & & & 24.79 & 0.30 \\
\hline \multirow[t]{3}{*}{ SD 918} & 1 & $1.76 \mathrm{E}-01$ & 8.37E-01 & 4.7606 & 40.69 & \\
\hline & 2 & $1.76 \mathrm{E}-01$ & $8.38 \mathrm{E}-01$ & 4.7610 & 40.98 & \\
\hline & 3 & $1.72 \mathrm{E}-01$ & $8.18 \mathrm{E}-01$ & 4.7612 & 40.93 & \\
\hline Mean & & & & & 40.87 & 0.30 \\
\hline \multirow[t]{3}{*}{ SD 931} & 1 & $1.59 \mathrm{E}-01$ & $7.55 \mathrm{E}-01$ & 4.7610 & 40.65 & \\
\hline & 2 & $1.54 \mathrm{E}-01$ & 7.34E-01 & 4.7634 & 41.38 & \\
\hline & 3 & $1.49 \mathrm{E}-01$ & 7.12E-01 & 4.7627 & 41.36 & \\
\hline Mean & & & & & 41.13 & 0.83 \\
\hline
\end{tabular}




\section{Table 5. Minimum Acceptable Data Quality Objectives and QA/QC for Groundwater Boron Isotopic Composition}

\begin{tabular}{|c|c|c|c|c|}
\hline Analyte & \multicolumn{4}{|c|}{ Groundwater boron isotopic composition $\left(\delta^{11} \mathrm{~B}\right)$} \\
\hline Units and reference & \multicolumn{4}{|c|}{ Permil (\%) deviation from reference standard NIST SRM 951} \\
\hline Formula & $\delta^{11} B_{\text {sample }}(\% o)=$ & \multicolumn{2}{|l|}{$R_{\text {sample }}$} & $\times 1000$ \\
\hline Method & \multicolumn{4}{|c|}{$\begin{array}{l}\text { Multi-collector Inductively Coupled Plasma Mass Spectrometry } \\
\text { (MC-ICP-MS) }\end{array}$} \\
\hline $\begin{array}{l}\text { Mass Bias } \\
\text { Correction }\end{array}$ & \multicolumn{4}{|c|}{$\begin{array}{l}\text { For each sample, bracket with analyses of NIST SRM } 951 \text { to calculate } \delta^{11} B \text { using } \\
\text { the above formula }\end{array}$} \\
\hline \multirow[t]{6}{*}{ Reference materials } & \multicolumn{4}{|c|}{$\begin{array}{l}\text { Each sample batch shall include two or more boron isotopic composition } \\
\text { reference standards that have been chemically purified using the same } \\
\text { chemistry as used for the samples. References standards will include NIST SRM } \\
951 \text { as a primary standard and one or both of the IAEA boron isotopic } \\
\text { standards (Gonfiantini et al., 2003) as secondary standards. Seawater } \\
\text { standards NASS-4 and NASS-5 (Foster et al., 2010) may also be used as } \\
\text { secondary standards. Sample analyses will be considered to be accurate to } \\
\text { within the reported precision listed below when measured values for the } \\
\text { chemically purified reference standards fall within the following acceptance } \\
\text { criteria. }\end{array}$} \\
\hline & Standard & Reference $\delta^{11} B$ value & Acceptanc & e criteria \\
\hline & NIST SRM 951 & 0\%о (by definition) & $\pm 1 \%$ o $(-1$ & to $+1 \%$ ) \\
\hline & IAEA-B-2 & $+38.60 \pm 1.58 \% \circ(2 \sigma)$ & $\pm 2 \sigma(37.02$ & $40.18 \%$ o) \\
\hline & IAEA-B-3 & $-21.40 \pm 1.78 \%$ o $(2 \sigma)$ & $\pm 2 \sigma(-23.18$ & $0-19.62 \%$ ) \\
\hline & $\begin{array}{l}\text { NASS-4, } \\
\text { NASS-5 }\end{array}$ & $+39.61 \pm 0.04 \%$ o $(2 \sigma)$ & $\pm 1 \%$ o $(38.61$ & to $40.61 \%$ ) \\
\hline QC samples & \multicolumn{4}{|c|}{$\begin{array}{l}\text { One procedural blank and one sample duplicate per batch }(5-10 \% \text { of total } \\
\text { number of samples). Acceptance criteria for sample duplicate is agreement } \\
\text { within } 1 \% \text { o. }\end{array}$} \\
\hline Precision & \multicolumn{4}{|c|}{ Generally achievable: $\pm 0.2 \%$ (internal); $\pm 0.7 \%$ (external) } \\
\hline Data reporting & \multicolumn{4}{|c|}{$\begin{array}{l}\text { Unless otherwise stated, sample analyses will only be reported when the } \\
\text { above acceptance criteria for chemically purified reference standards and } \\
\text { sample duplicates are met. }\end{array}$} \\
\hline Reported precision & \multicolumn{4}{|c|}{$\begin{array}{l} \pm 1.0 \% \text { (external sample precision or reproducibility to be reported when } \\
\text { QA/QC acceptance criteria are met, unless otherwise stated) }\end{array}$} \\
\hline
\end{tabular}




\section{References}

Al-Ammar, A. S., Gupta, R. K., and Barnes, R. M., 2000. Elimination of boron memory effect in inductively coupled plasma-mass spectrometry by ammonia gas injection into the spray chamber during analysis. Spectroc. Acta Pt. B-Atom. Spectr. 55, 629-635.

Barth, S. R., 2000. Boron isotopic compositions of near-surface fluids: A tracer for identification of natural and anthropogenic contaminant sources. Water Air and Soil Pollution 124, 4960.

Byrne, R. H., Yao, W. S., Klochko, K., Tossell, J. A., and Kaufman, A. J., 2006. Experimental evaluation of the isotopic exchange equilibrium B-10(OH)(3)+B-11(OH)(4)(-) = B$11(\mathrm{OH})(3)+\mathrm{B}-10(\mathrm{OH})(-)(4)$ in acqueous solution. Deep-Sea Research Part IOceanographic Research Papers 53, 684-688.

Foster, G. L., 2008. Seawater pH, pCO2 and [CO2-3] variations in the Caribbean Sea over the last 130 kyr: A boron isotope and B/Ca study of planktic foraminifera. Earth and Planetary Science Letters 271, 254-266.

Foster, G. L., Pogge von Strandmann, P. A. E., and Rae, J. W. B., 2010. Boron and magnesium isotopic composition of seawater. Geochem. Geophys. Geosyst. 11, -.

Gaillardet, J., Lemarchand, D., Gopel, C., and Manhes, G., 2001. Evaporation and sublimation of boric acid: Application for boron purification from organic rich solutions. Geostandards Newsletter-the Journal of Geostandards and Geoanalysis 25, 67-75.

Gonfiantini, R., Tonarini, S., Groning, M., Adorni-Braccesi, A., Al-Ammar, A. S., Astner, M., Bachler, S., Barnes, R. M., Bassett, R. L., Cocherie, A., Deyhle, A., Dini, A., Ferrara, G., Gaillardet, J., Grimm, J., Guerrot, C., Krahenbuhl, U., Layne, G., Lemarchand, D., Meixner, A., Northington, D. J., Pennisi, M., Reitznerova, E., I, R., Sugiura, N., Surberg, R., Tonn, S., Wiedenbeck, M., Wunderli, S., Xiao, Y. K., and Zack, T., 2003. Intercomparison of boron isotope and concentration measurements. Part II: Evaluation of results. Geostandards Newsletter-the Journal of Geostandards and Geoanalysis 27, 4157.

Guerrot, C., Millot, R., Robert, M., and Négrel, P., 2011. Accurate and High-Precision Determination of Boron Isotopic Ratios at Low Concentration by MC-ICP-MS (Neptune). Geostandards and Geoanalytical Research 35, 275-284.

Lemarchand, D., Gaillardet, J., Gopel, C., and Manhes, G., 2002a. An optimized procedure for boron separation and mass spectrometry analysis for river samples. Chemical Geology 182, 323-334.

Lemarchand, E., Schott, J., and Gaillardet, J., 2002b. Isotopic fractionation related to boron sorption on humic acids. Geochimica et Cosmochimica Acta 66, A446-A446.

Singleton, M. J., Roberts, S. K., Moran, J. E., and Esser, B. K., 2011. California GAMA Domestic Wells: Nitrate and Water Isotopic Data for Tulare County. Lawrence Livermore National Laboratory LLNL-TR-450497.

Tirez, K., Brusten, W., Widory, D., Petelet, E., Bregnot, A., Xue, D. M., Boeckx, P., and Bronders, J., 2010. Boron isotope ratio (delta B-11) measurements in Water Framework Directive monitoring programs: comparison between double focusing sector field ICP and thermal ionization mass spectrometry. Journal of Analytical Atomic Spectrometry 25, 964-974. 
Widory, D., Kloppmann, W., Chery, L., Bonnin, J., Rochdi, H., and Guinamant, J. L., 2004. Nitrate in groundwater: an isotopic multi-tracer approach. Journal of Contaminant Hydrology 72, 165-188.

Widory, D., Petelet-Giraud, E., Negrel, P., and Ladouche, B., 2005. Tracking the sources of nitrate in groundwater using coupled nitrogen and boron isotopes: A synthesis. Environmental Science \& Technology 39, 539-548. 


\section{Appendix A - Chemical Purification of Boron in Groundwater Samples for Isotopic Analysis}

1. INTRODUCTION

1.1. This Standard Operating Procedure (SOP) describes the laboratory procedure for the preparation of groundwater samples for the analysis of boron isotopes by MultiCollector Inductively Coupled Plasma Mass Spectrometry (MC-ICP-MS). The purpose of this SOP is to provide instructions for the analyst and other qualified laboratory personnel for performing these analyses in support of the Groundwater Ambient Monitoring and Assessment (GAMA) Program of the California State Water Resources Control Board (SWRCB). This SOP was written for the Environmental Radiochemistry Group of the Chemical Sciences Division at Lawrence Livermore National Laboratory.

2. SCOPE AND APPLICATION

2.1. This SOP describes the methods for separating boron from groundwater and other natural waters using ion exchange resin Amberlite IRA 743. In this technique, boron is dissolved in a neutral to basic solution, and sorbed to the surface of Amberlite IRA 743 resin beads on an ion exchange column. The resin is washed with neutral and basic solution to remove ions other than boron from the resin. Boron is then retrieved by washing the resin with an acidic solution. Purified samples are analyzed for boron isotope composition following the procedure described in Appendix B of this report.

3. DEFINITIONS

3.1. B - Boron

3.2. MC-ICP-MS - Multi-collector inductively coupled plasma mass spectrometer

3.3. $\mathrm{MQ}-$ Milli-Q $18 \mathrm{M} \Omega-\mathrm{cm}$ resistivity Millipore Water

3.4. ng - nanogram 


\section{PERSONNEL TRAINING}

4.1. Technicians must meet all institutional safety and training requirements for performing wet chemical procedures

5. MATERIALS AND EQUIPMENT

5.1. Poly-Prep disposable polyethylene columns for ion exchange chromatography (Bio-Rad)

5.2. $7 \mathrm{~mL}$ Teflon vials with screw caps (Savillex)

5.3. $15 \mathrm{~mL}$ Teflon vials with screw caps (Savillex)

5.4. Autopipette with pipette tips (Eppendorf)

5.5. $1 \mathrm{~mL}$ disposable plastic pipettes (Falcon)

5.6. $2 \mathrm{~mL}$ disposable polyethylene centrifuge tubes with caps (Eppendorf)

5.7. Temperature-adjustable hot plate (VWR)

5.8. Heat lamp

5.9. Ultrasonicator

6. REAGENTS

6.1. $\quad 18.2 \mathrm{M} \Omega-\mathrm{cm} \mathrm{H}_{2} \mathrm{O}-\mathrm{MQ}$ water (Millipore)

6.2. Basic $\mathrm{H}+$ soap (Shaklee)

6.3. $2 \% \mathrm{HNO}_{3}$ (SeaStar)

6.4. $2 \% \mathrm{NH}_{4} \mathrm{OH}$ (SeaStar)

6.5. Amberlite IRA 743 ion exchange resin, 100-200 mesh (Rohm and Haas) 


\section{PROCEDURES}

7.1. These methods have been adapted from Lemarchand et al. (2002), Foster (2008), and Guerrot et al. (2011). The analyst is referred to these references for further detail regarding the methods described here.

7.2. Boron concentrations in each water sample are determined by ion chromatography.

7.3. Teflon beakers are cleaned after each use using the following procedure:

7.3.1. Rinse each beaker thoroughly with $\mathrm{MQ}$ water.

7.3.2. Soak beakers in $M Q$ water with dilute Basic $H+$ soap for at least 6 hours. Rinse off soap using MQ water, and use clean wipers to scrub the insides of the beakers, ensuring that any precipitated material has been removed.

7.3.3. Heat beakers in simmering $7 \mathrm{M} \mathrm{HNO}_{3}$ for at least 8 hours. Allow beakers to cool, then rinse with $\mathrm{MQ}$ water.

7.3.4. Heat beakers in simmering $8 \mathrm{M} \mathrm{HCl}$ for at least 8 hours. Allow beakers to cool, then rinse with $\mathrm{MQ}$ water.

7.3.5. Allow beakers to dry. Beakers are ready for use when dry.

7.4. Calculate the volume of water of each groundwater sample required to obtain $\sim 500 \mathrm{ng}$ of boron. Pipette the approximate volume of sample into a tareweighted $15 \mathrm{~mL}$ Teflon beaker.

7.5. Dry down sample using a hot plate set at $\sim 65^{\circ} \mathrm{C}$ with a heat lamp. Monitor samples to ensure samples do not bubble. Remove samples from heat at or immediately before they are completely dry.

7.6. Pipette $1 \mathrm{~mL} \mathrm{MQ}$ water into each Teflon beaker. Pipette $25 \mu \mathrm{L} 2 \% \mathrm{NH}_{4} \mathrm{OH}$ into each Teflon beaker. Sonicate each beaker for at least $10 \mathrm{~min}$ to ensure the sample is completely in solution. If precipitate is still present in the beaker, add another $1 \mathrm{~mL}$ of $\mathrm{MQ}$ water and sonicate for $10 \mathrm{~min}$, or heat on hot plate for at least $30 \mathrm{~min}$. 
7.7. If Amberlite IRA 743 resin is not 100-200 mesh size, crush and sieve resin beads to produce resin of the requisite size. Clean the 100-200 mesh fraction using three washes each of $\mathrm{MQ}$ water, $2 \% \mathrm{HNO}_{3}, \mathrm{MQ}$ water, $2 \% \mathrm{NH}_{4} \mathrm{OH}$, and $\mathrm{MQ}$ water. After each wash, allow the resin to settle and pour off the supernate.

7.8. Prepare a $500 \mu \mathrm{L}$ Amberlite IRA 743 resin bed in a Poly-Prep column. Condition the resin bed with at least $2 \mathrm{~mL}$ of $2 \% \mathrm{HNO}_{3}, \mathrm{MQ}$ water, $2 \% \mathrm{NH}_{4} \mathrm{OH}$, and $\mathrm{MQ}$ water.

7.9. Load the contents of the Teflon beaker dropwise onto the Amberlite IRA 743 resin bed using a disposable pipette. Rinse the Teflon beaker twice with $0.5 \mathrm{~mL} \mathrm{MQ}$ water, each time loading the contents onto the resin bed. Boron should now be affixed to the resin.

7.10. Rinse the resin bed with $2 \mathrm{~mL} 2 \% \mathrm{NH}_{4} \mathrm{OH}$, followed by $2 \mathrm{~mL} \mathrm{MQ}$ water.

7.11. Place a clean, labeled $7 \mathrm{~mL}$ Teflon beaker below the column. Elute the boron affixed to the resin by rinsing the column with $4 \mathrm{~mL} 2 \% \mathrm{HNO}$, collecting the eluate in the beaker.

7.12. Dry down sample using a hot plate set at $\sim 65^{\circ} \mathrm{C}$ with a heat lamp. Remove samples from heat at or immediately before they are completely dry. Bring up sample in $2 \mathrm{~mL} 2 \% \mathrm{HNO}_{3}$.

7.13. Transfer sample to a $2 \mathrm{~mL}$ centrifuge tube for analysis by MC-ICP-MS. See Appendix B for MC-ICP-MS analytical procedures.

\section{QUALITY ASSURANCE / QUALITY CONTROL}

8.1. A procedural blank is to be run with each batch of samples.

8.2. At least one sample in each batch is to be run in duplicate. Duplicate values should fall within the analytical uncertainty determined for the analysis (typically better than $\pm 1 \%$ )

8.3. Reference materials SRM $951\left(\delta^{11} B=0 \%\right.$, by definition), IAEA-B-2 ( $\delta^{11} B=+38.60$ $\pm 0.79 \%$, Gonfiantini et al., 2003), and IAEA-B-3 ( $\delta^{11} B=-21.40 \pm 0.89 \%$, Gonfiantini et al., 2003) are to be processed with each batch of samples. Accuracy 
of analysis will be verified by analyzing these standards. Seawater standards NASS-4 and NASS-5 (39.61 $\pm 0.04 \%$ o, Foster et al., 2010) may also be used.

\section{SAFETY PRECAUTIONS}

9.1. General laboratory safety practices must be followed. Safety glasses, a lab coat, and hand protection must be worn when handling samples, acids, and bases.

9.2. The analyst should use special caution when adding acids or bases to samples.

10. REFERENCES

10.1. Foster $\mathrm{GL}$. 2008. Seawater $\mathrm{pH}, \mathrm{pCO}_{2}$ and $\left[\mathrm{CO}_{3}{ }^{2-}\right]$ variations in the Caribbean Sea over the last $130 \mathrm{kyr}$ : a boron isotope and B/Ca study of planktic foraminifera. Earth and Planetary Science Letters 271, 254-266.

10.2. Foster GL; Pogge von Strandmann PAE; Rae JWB. 2010. Boron and magnesium composition of seawater. Geochemistry Geophysics Geosystems 11, 10p.

10.3. Gonfiantini R and 30 others. 2003. Intercomparison of boron isotope and concentration measurements, Part I: evaluation of results. Geostandards Newsletter 27, 41-57.

10.4. Guerrot, C., Millot, R., Robert, M., and Négrel, P., 2011. Accurate and HighPrecision Determination of Boron Isotopic Ratios at Low Concentration by MCICP-MS (Neptune). Geostandards and Geoanalytical Research 35, 275-284.

10.5. Lemarchand D, Gaillardet J; Gopel C; Manhes G. 2002. An optimized procedure for boron separation and mass spectrometry analysis for river samples. Chemical Geology 182, 323-334. 


\section{Appendix B - Measurement of $\delta^{11} B$ in Groundwater Samples}

1. INTRODUCTION

1.1. This Standard Operating Procedure (SOP) describes the laboratory procedure for the analysis of prepared groundwater samples for boron isotope composition by Multi-Collector Inductively Coupled Plasma Mass Spectrometry (MC-ICP-MS). The purpose of this SOP is to provide instructions for the analyst for performing these analyses in support of the Groundwater Ambient Monitoring and Assessment (GAMA) Program of the California State Water Resources Control Board (SWRCB). This SOP was written for the Environmental Radiochemistry Group of the Chemical Sciences Division at Lawrence Livermore National Laboratory.

2. SCOPE AND APPLICATION

2.1. This SOP describes the methods for analyzing boron in processed groundwater samples. Samples are processed for boron chemical separation and purification following the procedures in Appendix A of this report. Boron isotope composition measurements are obtained using MC-ICP-MS. In this technique, a sample is introduced to the instrument in $2 \% \mathrm{HNO}_{3}$ to the plasma through a nebulizer and spray chamber. The sample is ionized when it reaches the $7000 \mathrm{~K}$ plasma, at which point it passes through sampler and skimmer cones kept at high vacuum. The ion beam is split into mass/charge beams when it encounters the magnetic sector mass analyzer. The separate mass/charge beams are detected by an array of Faraday cups, and the electronic signals produced are converted to ratios.

2.2. These procedures were designed for analysis on a Thermo Neptune MC-ICP-MS. Although analysis can be performed on other MC-ICP-MS instruments (i.e. Nu Plasma, MicroMass IsoProbe), doing so may require modification of these procedures.

3. DEFINITIONS

3.1. B - Boron

3.2. MC-ICP-MS - Multi-collector inductively coupled plasma mass spectrometer 
3.3. $\mathrm{M}-$ Molar

3.4. $\mathrm{MQ}-$ Milli-Q $18 \mathrm{M} \Omega--\mathrm{cm}$ resistivity Millipore Water

3.5. ng - nanogram

3.6. $\mathrm{ppb}$ - part(s) per billion

3.7. NIST - National Institute of Standards and Technology

4. PERSONNEL TRAINING

4.1. Technicians must meet all institutional safety and training requirements for performing wet chemistry and mass spectrometry procedures. Technicians will handle weak acids and bases in these procedures and must wear proper personal protective equipment.

5. MATERIALS AND EQUIPMENT

5.1. Neptune MC-ICP-MS (Thermo)

5.2. $2 \mathrm{~mL}$ plastic centrifuge tubes (Eppendorf)

5.3. X-skimmer cone (Thermo)

6. REAGENTS

6.1. $2 \% \mathrm{HNO}_{3}$ (SeaStar)

6.2. $2 \% \mathrm{HNO}_{3}+0.05 \mathrm{M} \mathrm{HF}$ (SeaStar)

6.3. NIST SRM 951 boric acid standard solution, 100 ppb (NIST)

\section{PROCEDURES}

7.1. See Appendix A of this report for chemical purification technique to be used prior to analysis. 
7.2. Dilute SRM 951 boric acid standard solution to $\sim 100 \mathrm{ppb}$. It is critical that boron concentration of bracketing standard is within $25 \%$ of boron concentration in sample (Guerrot et al., 2011).

7.3. Instrument Setup and Calibration

7.3.1. These methods have been adapted from Lemarchand et al. (2002), Foster (2008), and Guerrot et al. (2011). The analyst is referred to these references for further detail regarding the methods described here.

7.3.2. Start up MC-ICP-MS, allowing instrument to warm up for at least 1 hour before tuning. Tune MC-ICP-MS using 100 ppb SRM 951 boric acid standard. Best analytical results tend to be achieved if the instrument is tuned for maximum stability rather than maximum sensitivity (Guerrot et al., 2011).

7.3.3. After tuning, rinse the sample input system using $2 \% \mathrm{HNO}_{3}+0.05 \mathrm{M} \mathrm{HF}$ for 2-3 minutes. After rinsing, allow the sample input system to uptake a $2 \%$ $\mathrm{HNO}_{3}$ solution for 5 minutes. Perform a blank measurement of this $2 \% \mathrm{HNO}_{3}$ solution, using this result to blank-correct the following sample or standard measurement.

7.3.4. Perform 3 to 5 measurements of SRM 951 boric acid standard, washing and rinsing the sample input system after each measurement. Assess change in mass bias from each measurement. Mass bias change should be no more than $1 \%$ between each measurement of SRM 951. If over this threshold, run more standards, or re-tune instrument for increased stability.

\subsection{Analysis Procedure}

7.4.1. Perform a blank measurement in $2 \% \mathrm{HNO}_{3}$ prior to each standard or sample analysis. Subtract this measured ${ }^{11} \mathrm{~B}$ and ${ }^{10} \mathrm{~B}$ blank signal from the ${ }^{11} \mathrm{~B}$ and ${ }^{10} \mathrm{~B}$ signal for the sample and standard measurements.

7.4.2. Measure samples and standards using a standard-sample-standard bracketing routine. Be sure to assess intensity of sample prior to starting a run, in order to assure sample is within $25 \%$ of intensity of standard solution. If not, adjust dilution of sample or SRM standard solution 


\section{QUALITY ASSURANCE / QUALITY CONTROL}

8.1. A procedural blank is to be analyzed with each batch of samples.

8.2. At least one sample in each batch (approximately $10 \%$ of samples) is to be analyzed in duplicate. Duplicate values should fall within the analytical uncertainty determined for the analysis.

8.3. Reference materials SRM $951\left(\delta^{11} B=0 \%\right.$, by definition), IAEA-B-2 $\left(\delta^{11} B=+38.60\right.$ $\pm 1.58 \%$ ) , and IAEA-B-3 $\left(\delta^{11} \mathrm{~B}=-21.40 \pm 1.78 \%\right.$ ) are to be analyzed with each batch of samples. Accuracy of analysis will be verified by analyzing these standards. For IAEA-B-2 and IAEA-B-3, measurements should fall within stated error (Gonfiantini et al., 2003). For SRM 951, measurements should fall within \pm $1 \%$. Seawater standards NASS-4 and NASS-5 (39.61 $\pm 0.04 \%$, Foster et al., 2010) may also be used. Measurements should fall within $\pm 1 \%$ of the seawater $\delta^{11} \mathrm{~B}$ value.

8.4. If a standard is found to be outside of error, the standard should be re-run. If the second run is also outside of error, the standard analysis should be rejected. If two of three standards are rejected, the samples in the batch should be reprocessed through chemistry for re-analysis.

\section{SAFETY PRECAUTIONS}

9.1. General laboratory safety practices must be followed. Safety glasses and hand protection must be worn when handling samples, acids, and bases.

9.2. The analyst should use special caution when adding acids or bases to samples.

\section{REFERENCES}

10.1. Foster $\mathrm{GL}$. 2008. Seawater $\mathrm{pH}, \mathrm{pCO}_{2}$ and $\left[\mathrm{CO}_{3}{ }^{2-}\right]$ variations in the Caribbean Sea over the last $130 \mathrm{kyr}$ : a boron isotope and $\mathrm{B} / \mathrm{Ca}$ study of planktic foraminifera. Earth and Planetary Science Letters 271, 254-266.

10.2. Foster GL; Pogge von Strandmann PAE; Rae JWB. 2010. Boron and magnesium composition of seawater. Geochemistry Geophysics Geosystems 11, 10p. 
10.3. Gonfiantini R et al. 2003. Intercomparison of boron isotope and concentration measurements, Part I: evaluation of results. Geostandards Newsletter 27, 41-57.

10.4. Guerrot, C., Millot, R., Robert, M., and Négrel, P., 2011. Accurate and HighPrecision Determination of Boron Isotopic Ratios at Low Concentration by MCICP-MS (Neptune). Geostandards and Geoanalytical Research 35, 275-284.

10.5. Lemarchand D, Gaillardet J; Gopel C; Manhes G. 2002. An optimized procedure for boron separation and mass spectrometry analysis for river samples. Chemical Geology 182, 323-334. 


\section{Appendix C - Submission of Groundwater Boron Isotopic Data to Geotracker GAMA in EDF Format}

1. INTRODUCTION

1.1. This Standard Operating Procedure (SOP) describes the laboratory procedure for uploading boron isotope data to GeoTracker GAMA. The purpose of this SOP is to provide instructions for the analyst or other qualified laboratory personnel for properly compiling the information necessary for creating EDFCL (electronic data file control limit) and EDFFLAT (electronic data file flat format).

2. SCOPE AND APPLICATION

2.1. This SOP describes the methods for the creation of EDFCL and EDFFLAT files for uploading boron isotope data to GeoTracker GAMA.

2.2. The EDFCL contains $Q A / Q C$ (Quality Assurance/Quality Control) information regarding the boron isotopic analysis. The specific $Q A / Q C$ procedures are discussed in detail in Appendix $A$ and $B$ of this report. This SOP is concerned with the development of $a$ properly-formatted EDFCL, containing QA/QC information pertinent to these analyses. The EDFCL must be submitted with each EDFFLAT. The EDFCL should be the same for each boron isotope analysis, and only needs to be revised if the QA/QC methods are revised.

2.3. The EDFFLAT contains all of the information specific to each individual boron isotope analysis (date and time of collection, preparation method used, analytical method used, etc.). These data must be formatted properly for valid submission to the GeoTracker database. Valid value codes (VVLs) must be used. In the case where a VVL does not exist for a particular parameter, new codes can be requested (see the GeoTracker EDF Data Dictionary for more information).

3. DEFINITIONS

3.1. EDFCL - Electronic Data File Control Limit

3.2. EDFFLAT - Electronic Data File Flat Format

3.3. VVL - Valid value codes 
3.4. ESI - Electronic Submittal of Information

3.5. NIST - National Institute of Standards and Technology

3.6. IAEA - International Atomic Energy Agency

4. PROCEDURES

\subsection{EDFCL}

4.1.1. Follow the instructions on the GeoTracker GAMA website (ESI information can be found on the GeoTracker help page). VVLs for data submission can be queried on this site.

4.1.2. The CLCODE is used to denote the QA/QC methods employed in analytical measurements uploaded to GeoTracker. Each QA/QC method is associated with a VVL. In this study, we utilize several QA/QC methods (see Appendix A and B); each of these methods is associated with a CLCODE VVL. See below for the VVLS used in this study, as well as a description of the QA/QC procedures utilized to satisfy the requirements of each CLCODE VVL.

4.1.2.1. LCC - Laboratory Continuing Calibration Accuracy. We perform chemical purification and isotopic measurement of NIST SRM 951, IAEA-B-2, and IAEA-B-3 to continually establish measurement accuracy.

4.1.2.2. LIC - Laboratory Initial Calibration Accuracy. We performed chemical purification and isotopic measurement of NIST SRM 951, IAEA-B-2, and IAEA-B-3 to establish initial accuracy.

4.1.2.3. LLR - Laboratory Established Precision for Lab Replicates. We set $\pm 1.0 \%$ o limits to laboratory replicates. One pair of replicates is run with each batch of samples.

4.1.2.4. SRAD - Standard Reference Accuracy Defined by Agency/Manufacturer. Accuracy of NIST SRM 951 is defined as $0.0 \%$ by NIST. Accuracy of IAEA-B2 is defined as $+13.80 \%$ by IAEA. Accuracy of IAEA-B-3 is defined as -21.40 \%o by IAEA. 
4.1.2.5. SRMP - Standard Reference Material Precision Limits Determined by Lab. We define limits of $\pm 1.0 \%$ of NIST SRM 951. We define limits of $\pm 1.58 \%$ o ( $2 \sigma$ uncertainty of recommended value; Gonfiantini et al., 2003) for IAEA-B2 . We define limits of $\pm 1.78 \%$ o ( $2 \sigma$ uncertainty of recommended value; Gonfiantini et al., 2003) for IAEA-B-3.

4.2. EDFFLAT. Follow the instructions on the GeoTracker GAMA website (ESI information can be found on the GeoTracker help page). VVLs for data submission can be queried on this site.

5. QUALITY ASSURANCE / QUALITY CONTROL

5.1. All data should be thoroughly investigated for errors in translation to the EDF format. 